\title{
EDUCAÇÃO AMBIENTAL E EXAME NACIONAL DO ENSINO MÉDIO: (COR)RELAÇÕES E IMPLICAÇÕES DE UMA ABORDAGEM EM MACROESCALAS GEOGRÁFICAS
}

\author{
Luiz Ricardo Oliveira Santos ${ }^{1}$ \\ Rosemeri Melo e Souza ${ }^{2}$ \\ Jailton de Jesus Costa ${ }^{3}$
}

\begin{abstract}
Resumo
O Exame Nacional do Ensino Médio (ENEM) foi instituído para avaliar essa etapa de ensino, servindo também como meio de acesso ao ensino superior nas principais universidades do país. Apesar das reformulações pelas quais tem passado, o seguimento restrito de sua matriz de referência pode comprometer a discussão de temas socioambientais em escala local. O objetivo do presente estudo foi argumentar acerca das implicações trazidas pelo ENEM para a discussão dessas questões no âmbito escolar. Para isso, foram coletados dados bibliográficos, como artigos indexados e documentais, através da análise das provas de Ciências Humanas e Ciências da Natureza aplicadas entre 2012 e 2016. Sua análise comprovou o pouco número de questões que trataram de temas socioambientais em escala local, prevalecendo as macroescalas global/nacional. Constatou-se, assim, que o ENEM, raramente, aborda questões locais em suas provas, devendo a escola utilizar outros instrumentos para ampliar discussões dessa natureza.

Palavras-chave: Ciências ambientais. Educação Ambiental. Educação Básica. ENEM.
\end{abstract}

\section{ENVIRONMENTAL EDUCATION AND BRAZILIAN HIGH SCHOOL NATIONAL EXAM: (COR)RELATIONS AND IMPLICATIONS OF AN APPROACH IN GEOGRAPHIC MACROSCALES}

\begin{abstract}
The Brazilian High School National Exam (ENEM) was instituted to evaluate this teaching stage, also serving to access higher education in the main Brazilian universities. Despite the reformulations it has undergone, the restricted follow-up of its reference matrix can compromise the discussion of socioenvironmental issues on a local scale. This study aimed to argue about the implications of ENEM for the discussion of socioenvironmental issues on a local scale in the school context. For this, bibliographic data were collected as indexed and documentary articles, through the analysis of the tests of Human Sciences and Natural Sciences, applied from 2012 to 2016, which proved the few issues that dealt with local socioenvironmental issues in those years, prevailing global/national macroscales. Thus, ENEM rarely addressed local issues in its tests, and the school should use other instruments to expand discussions of this nature.
\end{abstract}

Keywords: Environmental Sciences. Environmental Education. Basic Education. ENEM.

\footnotetext{
${ }^{1}$ Mestrando em Ensino das Ciências Ambientais, Universidade Federal de Sergipe (PROF-CIAMB/UFS). E-mail: santos.Iro@gmail.com

${ }^{2}$ Doutora em Desenvolvimento Sustentável. Professora Titular do PRODEMA/UFS, PPGEO/UFS e PPGECIA/UFS. E-mail: rome@ufs.br

${ }^{3}$ Doutor em Geografia. Professor Titular do PROF-CIAMB/UFS e PRODEMA/UFS.

E-mail: jailton@ufs.br
} 


\section{EDUCACIÓN AMBIENTAL Y EXAMEN NACIONAL DE LA ENSEÑANZA MEDIA: (COR)RELACIONES E IMPLICACIONES DE UN ENFOQUE EN MACROESCALAS GEOGRÁFICAS}

\section{Resumen}

Se instituyó el Examen Nacional de la Enseñanza Media (ENEM) para evaluar la etapa de enseñanza media, pero también sirvió para acceder a la Enseñanza Superior en las principales universidades de Brasil. A pesar de las reformulaciones por las que ha pasado, el seguimiento restringido de su matriz de referencia puede comprometer la discusión de temas socioambientales a escala local. El objetivo de este estudio fue argumentar acerca de las implicaciones del ENEM en la discusión de cuestiones socioambientales a escala local en el ámbito escolar. Para ello, se recolectaron datos bibliográficos, como artículos indexados y documentales, por medio del análisis de las pruebas de Ciencias Humanas y de Ciencias de la Naturaleza, aplicadas de 2012 a 2016, y que comprobaron el poco número de cuestiones sobre temas socioambientales a escala local en estos años, prevaleciendo las macroescalas global/nacional. Se constató que el ENEM raramente abordó cuestiones locales en sus pruebas, así, la escuela debe utilizar otros instrumentos para ampliar discusiones de esa naturaleza.

Palabras clave: Ciencias Ambientales. Educación Ambiental. Educación Básica. ENEM.

\section{Introdução}

Pensar, sentir, compreender, pertencer e agir - diversas palavras que podem ser utilizadas como ponto inicial em uma discussão acerca do ambiente, termo que pode designar diversas possibilidades de análise ou convergir para um local múltiplo que abrange essas interações, ideologias e paradigmas. O saber ambiental ascende como necessidade de integração entre os saberes, pensamentos e valores individuais e coletivos, frente a uma crise socioambiental. É observado através da multiplicidade de sentidos, que vão além da articulação científica e de saberes individuais e tem, em suas ações, as representações das ideologias advindas dos diferentes grupos que o fazem (LEFF, 2009a). Desse modo, perceber e agir é, de certa forma, pertencer.

Essa relação de pertencimento pode ser estimulada através de ações educativas que se interliguem com as vivências dos sujeitos diretamente envolvidos nas práticas desempenhadas, que dotam de significados intrínsecos os conceitos abordados e tendem a se aproximar dos valores próprios, construídos pela sociedade, integrando-se ao seu lugar ${ }^{4}$. Não apenas através de espaços físicos, delimitados por muros, fronteiras, territórios ou exames de verificação da aprendizagem e autoavaliação, a construção de saberes deve ser pautada em sensações, respeito e cumplicidade.

Entre os exames de verificação de aprendizagem está o Exame Nacional do Ensino Médio (ENEM), que possui relação com uma série de políticas públicas, associadas a reformulações tanto na forma de acesso ao ensino superior quanto na aplicação de suas provas como estabelecimento de políticas públicas. Instituído em 1998 pelo Instituto Nacional de Estudos e Pesquisas Educacionais Anísio Teixeira (INEP), órgão do Ministério da Educação (MEC), o ENEM teve, como objetivo inicial, a avaliação do aprendizado dos alunos que concluíam esta etapa do ensino, além de fornecer subsídios para o ingresso em cursos de nível superior e profissionalizantes, por meio de um exame de referência (BRASIL, 1998).

Com o passar dos anos, essa política foi sendo aprimorada e passou a servir, também,

\footnotetext{
${ }^{4}$ Em consonância com Callai (2004), o lugar é um espaço que possui relação com a vida e o trabalho das pessoas, que resgata sentimentos de identidade, pertencimento e que ascende na forma como tais sujeitos usufruem desse espaço, sendo importante na compreensão do mundo a partir da leitura da realidade.
} 
de instrumento principal de acesso ao ensino superior público, através do Sistema de Seleção Unificada (SiSU), por meio da adesão de várias universidades, que substituíram seus vestibulares tradicionais pela prova do ENEM, o que exigiu reformulação de sua matriz. Do mesmo modo, também permitiu o acesso ao ensino superior privado pelo Programa Universidade para Todos (PROUNI), que tem como finalidade a concessão de bolsas de estudo integrais e parciais em cursos de graduação e sequenciais de formação específica. Criado pelo Governo Federal em 2004 e institucionalizado pela Lei $\mathrm{n}^{\circ} 11.096$ em 13 de janeiro de 2005, oferece, em contrapartida, isenção de tributos às instituições que aderirem ao Programa.

O PROUNI também possui ações conjuntas de incentivo à permanência estudantil nas instituições, como a Bolsa Permanência e, ainda, o Fundo de Financiamento Estudantil (Fies), que possibilita ao bolsista parcial financiar parte da mensalidade não coberta pela bolsa do programa. Com o ENEM, outras oportunidades de acesso ao ensino superior foram implementadas, a exemplo do Fies, por meio do qual o governo federal investe subsídios públicos em instituições privadas. Apesar dos avanços em relação ao crescimento do acesso às faculdades e universidades, pode-se analisar o financiamento por dois vieses: a problemática da dívida estudantil com bancos públicos, mascarada pelo título de investimento educacional, e o princípio do direcionamento de valores, que poderiam ser investidos em universidades públicas, em um programa de valorização destas.

A partir de 2009, o exame passou a ser dividido em quatro grandes áreas, a saber: Ciências da Natureza e suas Tecnologias, Ciências Humanas e suas Tecnologias, Códigos e Linguagens e Matemática e suas Tecnologias, além de um exame de Redação. São elaboradas 45 questões de cada área, perfazendo um total de 180, aplicadas em dois dias de prova de múltipla escolha, legando a parte subjetiva ao texto dissertativo-argumentativo proposto. A temática das questões e, principalmente da redação, objetiva versar sobre temas atuais e contextualizados, que insiram o candidato em um contexto aplicado, no qual sejam valorizados os Direitos Humanos, integrando conhecimentos das várias áreas do saber científico, de forma a possibilitar uma abordagem interdisciplinar e que leve o aluno/candidato a resolver problemas da vida em sociedade.

Contudo, apesar da reorganização e fortalecimento do ENEM, trazidos pela reformulação de sua matriz, quando observadas as questões socioambientais, estas se encontram ainda de forma fragmentada e pouco abrangente quanto à escala geográfica local, pois são abordadas questões gerais e que não valorizam a multiplicidade de olhares e o processo de formação do país, principalmente sua regionalização, podendo privilegiar, assim, regiões específicas. Desse modo, pode-se questionar se o exame serve para trazer à discussão os problemas socioambientais ou para criar um modelo de escola que busca resultados e que, por isso, pode ter sua autonomia comprometida através do seguimento de sua matriz curricular de referência e de sistemas públicos e privados de construção de materiais de ensino, como o Programa Nacional do Livro Didático (PNLD).

Nesse contexto, o ensino, quando pautado somente nesses programas, pode acarretar problemas como a reprodução da ciência cartesiana, insuficiente para responder às questões de um mundo dinâmico, e a abertura de lacunas na formação cidadã dos educandos, comprometendo a autonomia docente. Nesse sentido, a escola pode retomar à posição de mera transmissora do que deve ser ensinado, a fim de atender a interesses mercantilistas, negligenciando as discussões sobre temas de interesse da comunidade (BELTRÃO, 2014). Dentre os temas ocultados nesse fazer escolar, pode-se citar a questão dos problemas socioambientais locais, uma vez que o objetivo principal do ensino conteudista é desenvolver a matriz de referência do ENEM, que encontra nos sistemas de ensino o meio concreto de transmissão de conteúdos que fundamentam o planejamento pedagógico.

A escola brasileira adotou, depois da implantação do ENEM, um modelo de avaliação pautado apenas nas diretrizes da prova e, com isso, abriu, cada vez mais, mão do planejamento coletivo e do pensamento crítico, que considera os múltiplos saberes, atribuindo aos docentes e 
discentes a tarefa de compreender o que é solicitado pelo exame (SANTOS; COSTA; MELO E SOUZA, 2017, 2018a, 2018b). Do mesmo modo, observa-se que, através da adoção de tais parâmetros, a escola pôde voltar-se às práticas tradicionais de ensino, como a simples transmissão de conteúdos e centralização do docente como detentor do saber, repetindo práticas que ocorriam nos antigos exames vestibulares, que foram, parcialmente, substituídos pelo ENEM. Nesse sentido, a avaliação das práticas pedagógicas desenvolvidas pela escola pode encontrar empecilhos na integração entre políticas e sistemas de avaliação externas (de larga escala) e internas (da própria unidade de ensino).

Corrobora-se com Bauer, Alavarse e Oliveira (2015) quando argumentam que as reformas educacionais - entre as quais pode-se inserir o ENEM e as demais políticas públicas a ele associadas - possuem objetivos e características como: a centralização da avaliação, uma vez que esse processo característico das unidades de ensino passa a ser organizado em larga escala, ainda que paralelo às demais atividades realizadas pela escola; a descentralização da gestão, pois os resultados alcançados pelas unidades escolares passam a compor um rol comparativo entre as escolas do território nacional, atrelando as necessidades escolares apenas aos resultados obtidos, não dando, às maiores instâncias, condições de gerir o que de fato acontece no reduto escolar, possibilitando interpretações diversas; etc. Nessa égide, acentua-se uma valorização de resultados, que pode criar mecanismos que ocultem a verdadeira realidade escolar e possibilitem, ainda que inicialmente, a exclusão de estudantes que não alcancem resultados satisfatórios para manter a unidade bem avaliada perante os órgãos que a elaboram.

Nesse sentido, tais avaliações podem alimentar, como já discutido, a ocultação da realidade, ao desestimular os alunos que possuem necessidades alheias ao processo avaliativo e que se supõe que teriam resultados insatisfatórios. No entanto, a problemática da escola vai além de uma simples aderência às avaliações externas, devendo os gestores escolares ou das esferas do poder público preocupar-se com a redução das desigualdades entre os estudantes (BAUER; ALAVARSE; OLIVEIRA, 2015). Desse modo, a gestão integrada deverá possibilitar a ascensão da educação como uma totalidade, não apenas de maneira pontual, em escolas mais privilegiadas em relação à maioria das escolas do território nacional.

Com base nas reflexões apresentadas, pode-se levantar a seguinte questão: a escola contemporânea, que volta suas práticas para o ENEM, com a utilização de sistemas de ensino direcionados a esse exame, discute aspectos socioambientais de maneira eficaz, uma vez que a transversalidade do meio ambiente é algo complexo e que necessita de formação integral e holística?

O presente estudo tem por objetivo argumentar as implicações trazidas pelo ENEM para a discussão de questões socioambientais em escala local no âmbito escolar. Para atingir o objetivo proposto, foi realizada uma coleta de dados bibliográficos e documentais preliminares, analógicos e digitais, em diversas fontes disponibilizadas em órgãos da administração pública direta e indireta, a exemplo de teses, dissertações, livros, capítulos de livros, artigos científicos publicados em periódicos no banco de dados da Capes e instituições federais de ensino, anais de congressos, além de também terem sido analisadas as provas de Ciências Humanas e Ciências da Natureza do ENEM aplicadas de 2012 a 2016.

Foram selecionadas questões das provas anteriormente citadas que tivessem relação com aspectos naturais, sociais e culturais, desde que explanassem as interações entre seres vivos com o ecossistema em que estão inseridos, num aspecto mais ecologista, como também questões que abordassem a relação homem-natureza, incluindo a utilização dos recursos naturais, que exibe consequências positivas ou negativas para o ambiente.

Nessa perspectiva, primeiramente, foram discutidos os âmbitos da educação ambiental (EA), englobando os processos de formação intelectual do ser humano enquanto cidadão e as principais implicações para inserção da escala local nas discussões escolares. Posteriormente, foi realizada uma análise das questões do ENEM, (cor)relacionando seus princípios e temáticas a instrumentos de ensino, como o livro didático, elencando os principais desafios pedagógicos 
a serem superados na busca de caminhos alternativos para a formação de sujeitos (particip)ativos.

\section{O ENEM como desafio instrumental e pedagógico para o desenvolvimento de habilidades e atitudes em educação ambiental}

A Constituição Federal instituída em 1988 já citava a necessidade de se promover a EA em todos os níveis de ensino, a fim de se efetivar o direito dos cidadãos a um ambiente ecologicamente equilibrado, como também a promoção da conscientização pública para a preservação ambiental (BRASIL, 1988). Para além dos conceitos trazidos pela Constituição sobre a eficácia da conscientização e da preservação ambiental - sendo mais adequadamente referenciados os termos sensibilização e conservação ambiental - na busca pela inserção dos valores humanos nesse contexto, o avanço trazido pela carta magna está pautado, principalmente, no reconhecimento da EA enquanto processo de construção cidadã nas escolas, abrindo, também, espaço para seu desenvolvimento em ambientes externos a ela.

Com base nesses pressupostos, a EA pode ser reconhecida em dois âmbitos: o formal e o não-formal. O primeiro é desenvolvido nas propostas curriculares das disciplinas escolares, sendo essencial sua abordagem contínua e interdisciplinar, possibilitando a formação crítica e reflexiva dos educandos, sensibilizando-os acerca da atual crise socioambiental e do papel da humanidade em relação a tal fenômeno, como também motivando-os a tomar decisões frente às necessidades das futuras gerações. A EA não-formal, por sua vez, abrange espaços que vão além dos muros colegiais, envolvendo e trazendo à discussão os diversos sujeitos componentes das comunidades, que se integram e pertencem a determinados lugares, devendo buscar a integração entre a escola e diversos setores da sociedade (REIS; SEMÊDO; GOMES, 2012).

Ao passo que o homem é ensinado a agir conforme o modelo social atual, do ponto de vista socioambiental, a interação com os sistemas naturais se dá pela forma de uso dos recursos. A natureza é visualizada como oferta, meio de extração e objeto infinito, algo que lhes foi dado para ser usufruído e, por meio desse pensamento, visualiza-se o início da degradação ambiental, não somente embalada pela retirada desenfreada dos seus componentes.

A escola, mediante seu papel imprescindível para a formação humana, pela natureza de sua criação enquanto construção social, tem função de manter o sistema capitalista vigente. No entanto, não cabe à escola toda a culpa pela degradação ambiental, tendo em vista esse espaço enquanto construto social e, portanto, como discute Louis Althusser (1980), aparelho ideológico do Estado. Outrossim, não se deve julgar que todos os problemas socioambientais poderão ser resolvidos por inteiro na escola, mas sim que poderão ser refletidos e discutidos, estimulando a sensibilidade e posterior tomada de decisão.

O saber ambiental ${ }^{5}$ ascende como proposta de integração participativa, não mais tratando o ambiente pelos ramos da ecologia naturalista, conduzida pelas essências do ambiente puramente natural, dos fatores bióticos enquanto seres em interação com os abióticos, e sim a percepção do ambiente como um todo em sua complexidade, que abrange tanto as relações naturais aqui descritas como também compreende as relações humanas, sociais, econômicas, históricas e culturais e as formas como estas influenciam os sistemas ambientais, construindo, assim, novas realidades.

A importância das ações escolares no que tange à EA de maneira crítica e emancipatória permeia várias etapas, que vão desde a discussão dos paradigmas sociais que fundamentam a criação da escola como meio de reprodução do sistema capitalista, como também pela

\footnotetext{
${ }^{5}$ Consoante Leff (2009b), o saber ambiental problematiza o conhecimento que foi fragmentado em disciplinas no sentido de formar um novo campo de conhecimentos que rearticulem a relação sociedade-natureza, distanciada pelo desenvolvimento científico. Para isso, utilizam-se processos transdisciplinares que vão além das ciências ambientais, problematizando e transformando paradigmas hoje dominantes, na busca pela (re)totalização e internalização desse novo saber.
} 
necessidade de discussão das pequenas ações e o despertar crítico das individualidades como parte integrante de um ambiente dotado de valores culturais e históricos, significações e representatividades, que precisa despertar o "ser" natureza em detrimento do "ter" a natureza, valorizando o sentimento de pertencimento, de modo a englobar o seu lugar.

Avançando nas determinações trazidas pela Constituição Federal e instituindo diretrizes específicas para a EA, a posterior Política Nacional de Educação Ambiental (PNEA), instituída pela Lei 9.795/1999, garante que a EA deve perpassar por todos os níveis e modalidades de ensino, valorizando o pluralismo de ideias e articulando práticas interdisciplinares e transdisciplinares. A partir daí, tornou-se responsabilidade do Sistema Nacional do Meio Ambiente (SISNAMA), do sistema educacional, dos meios de comunicação e, principalmente, do poder público com participação da sociedade como um todo. No entanto, como ainda enfatiza a política, a EA não deve ser disciplina específica do currículo escolar devido a sua dimensão múltipla, integrada e à transversalidade do meio ambiente, excetuando os casos voltados aos aspectos metodológicos do processo em questão (BRASIL, 1999).

Ainda que se construa a educação para o ambiente no espaço escolar como algo essencial para o desenvolvimento crítico, consciente e emancipatório, tal enunciado, bastante utilizado nas ações escolares, é traduzido como atividades pontuais, projetos descontínuos e desintegrados. Quando realizadas, essas ações são tomadas como obrigação disciplinar, tendo espaço reduzido de tempo, apresentando a EA apenas como tema transversal, quando abordada nas disciplinas que melhor se assemelham, e não como tema motivador e gerador de discussões que abranjam todas as unidades letivas e que esteja presente no despertar para as questões socioambientais, principalmente de natureza local.

A abordagem insuficiente das ações de EA na educação básica (aqui tendo como base o ensino médio), se faz pelo desenvolvimento de técnicas tradicionais de ensino, como a adoção exclusiva de materiais - a exemplo do livro didático - confeccionados por sistemas privados de ensino, em algumas instituições privadas, e pelo PNLD, nas instituições públicas. Tais materiais, por vezes, são utilizados como cartilhas, que ditam os procedimentos e técnicas a serem propostas nas aulas. Não obstante, os livros utilizados pela escola podem estar dissociados e alheios à realidade dos discentes e das comunidades a que eles pertencem. Com isso, concorda-se com Sá e Ferreira (2015, p. 152), ao afirmarem que a escolha desse tipo de material deve "estar pautada na realidade dos atores da instituição escolar, pois as diferenças existem e precisam ser respeitadas, por isso, ao escolher o livro, a responsabilidade e o respeito são essenciais".

Somada à problemática do livro didático, a adoção das diretrizes do ENEM, que seleciona os candidatos para acesso ao ensino superior relaciona-se a uma tentativa de garantir o meio ambiente ecologicamente equilibrado à população, tal qual preconiza a Constituição, como também de trazer à discussão os aspectos da EA no ensino básico. Para isso, são formuladas questões que incentivem a tomada de decisão por parte de estudantes, que, muitas vezes, sequer tiveram a possibilidade de desenvolver competências e habilidades de maneira crítica, durante sua vivência escolar. Com isso, apesar dos crescentes avanços que são trazidos pelo ENEM e pelo PNLD, a ideia da discussão ambiental global pode ser interpretada como implicação ou barreira para o desenvolvimento de ações ambientais em nível local, ocultando o lugar, enquanto categoria geográfica de análise, dos currículos escolares, o que pode estar associado à insuficiente discussão ambiental nos espaços formais.

\subsection{Pensar e agir localmente: desafios pedagógicos e instrumentais do ENEM}

No Brasil, a dissociação da realidade local em conteúdos escolares parte, principalmente, dos conteúdos exigidos pelo ENEM, que trazem à tona assuntos como os impactos ambientais ocasionados pela ação antrópica, mas sem uma ampla discussão do caso, dando caráter mecânico e não crítico para o que o discente vive e, por vezes, causando baixo 
entendimento e desconexão em relação aos valores culturais deste, tornando o conteúdo abstrato e de difícil entendimento, fazendo que o espaço destinado às manifestações emergentes nos diferentes espaços educacionais seja restringido (BELTRÃO, 2014).

A política do exame pode ser visualizada a partir de pontos positivos e negativos em relação aos vestibulares tradicionais: por um lado, a evolução se deu na forma da abordagem das questões - mais contextualizadas com as diversas áreas do conhecimento, abrindo espaço para discussões interdisciplinares - por outro lado, a abrangência nacional dos conteúdos da prova fez que fossem perdidas as particularidades de cada vestibular e as questões voltadas às características regionais e/ou locais. Além do exposto, algumas questões podem priorizar regiões específicas do país, como também abordar situações desconexas com o que de fato acontece.

Conforme ensina Gusmão (2016), para que a efetividade do ensino da geografia, da biologia e das demais ciências ambientais seja convincente na formação consciente do aluno sobre a realidade circunscrita no espaço em que ele vive, é essencial que o professor o conduza para alcançar a compreensão espacial que vai da escala local à global, e finalmente chegar à compreensão maior que é a "sua realidade". Ainda de acordo com a mesma autora, a análise da realidade materializada no espaço geográfico precisa ser cumprida e, principalmente no ensino médio - segmento em que há possibilidades mais amadurecidas de diálogo -, esse objetivo deve ser atendido.

Muito tem-se falado em educação para a cidadania, mas de maneira, muitas vezes, irreal e inalcançável, burocrática, ligada ao positivismo e com soluções técnicas, definida em um ou vários objetivos que, no mais das vezes, consideram o sujeito - estudante - descolado do mundo em que vive, como se fosse um ser neutro e abstrato (CALLAI, 2001).

A lógica do ENEM, do PNLD, para escolas públicas, e de sistemas privados de ensino, que, em sua maioria, seguem a formatação exigida pelo primeiro, direcionam os discentes para uma formação de mercado e, principalmente, para os cursos mais elitizados. Essa metodologia pode ser defendida como uma tentativa de abranger características gerais e que desconsideram o processo de formação do povo brasileiro. De acordo com Macedo e Medeiros (2011, p. 10), ao analisarem a materialização das formações ideológicas da produção do novo ENEM, a "formação de profissionais marcados apenas pela ideologia predominante do mercado, bem como as precisões impostas pelo processo de globalização", desprezando as diferenças regionais, pressupondo-se que, dessa maneira, os candidatos a uma vaga no ensino superior se farão críticos, reflexivos e terão visão ampliada de mundo. Dessa forma, o conhecimento defendido pelo exame despreza as diferenças regionais, abrangendo macroescalas geográficas para se adequar às novas realidades mundiais, que, apesar de importantes, não devem configurar elementos para negação do lugar e suprimir a realidade discente, carregada de valores sociais e culturais.

Pode-se dizer que "a avaliação externa orienta e determina os objetivos e a extensão das disciplinas (em especial português e matemática, mas não menos as demais disciplinas, pois interfere nos tempos que a escola permite dedicar a estas)" (FREITAS, 2014, p. 1094). Nesse sentido, tais avaliações "influenciam o que a escola e o professor assumem como método e conteúdo a ser ensinado em suas aulas" (FREITAS, 2014, p. 1094).

A exemplo disso, ao analisar as provas de Ciências Humanas e suas Tecnologias, aplicadas entre os anos de 2012 a 2016, das 225 questões desses cinco anos, apenas 23 questões trouxeram à tona qualquer forma de debate ambiental, conforme pode-se analisar no Quadro 1 . Nesse contexto, as questões mais se adequam às macrotendências conservacionista e pragmática, que levam o aluno a relacionar as problemáticas ambientais pelo viés puramente natural - ou ecologista -, dissociado dos valores culturais de populações tradicionais presentes em interação com os ecossistemas, afastando-os da discussão cotidiana do seu lugar. 
Quadro 1 - Análise das questões de Ciências Humanas e suas Tecnologias (2012-2016) do ENEM.

\begin{tabular}{|c|c|c|c|c|}
\hline Ano & Caderno & Questão & Conteúdo Abordado & Escala \\
\hline \multirow{3}{*}{2012} & \multirow{3}{*}{$\begin{array}{l}\text { Caderno } \\
01\end{array}$} & 26 & Impactos ambientais & Global \\
\hline & & 38 & Impactos da irrigação & Nacional \\
\hline & & 42 & Uso da água & Global \\
\hline \multirow{4}{*}{2013} & \multirow{4}{*}{$\begin{array}{l}\text { Caderno } \\
01\end{array}$} & 14 & Biogeografia & Nacional \\
\hline & & 28 & Agricultura & Nacional \\
\hline & & 42 & Chuva ácida & Global \\
\hline & & 43 & Matrizes energéticas & $\begin{array}{l}\text { Regional } \\
\text { (Nordeste) }\end{array}$ \\
\hline \multirow{5}{*}{2014} & \multirow{5}{*}{$\begin{array}{l}\text { Caderno } \\
04\end{array}$} & 15 & Geração de energia & Nacional \\
\hline & & 16 & Climatologia & $\begin{array}{l}\text { Regional } \\
\text { (Norte) }\end{array}$ \\
\hline & & 18 & Salinização & Global \\
\hline & & 29 & Hidrografia & $\begin{array}{l}\text { Regional } \\
\text { (Norte) }\end{array}$ \\
\hline & & 45 & Desertificação & Global \\
\hline \multirow{6}{*}{2015} & \multirow{6}{*}{$\begin{array}{l}\text { Caderno } \\
01\end{array}$} & 01 & Biomas Brasileiros & Nacional \\
\hline & & 04 & Agrotóxicos & Nacional \\
\hline & & 27 & Intemperismo & Nacional \\
\hline & & 31 & Erosão & Global \\
\hline & & 32 & Hidrologia & $\begin{array}{l}\text { Regional } \\
\text { (Sudeste) }\end{array}$ \\
\hline & & 45 & Preservação da natureza & Nacional \\
\hline \multirow{5}{*}{2016} & \multirow{5}{*}{$\begin{array}{l}\text { Caderno } \\
03\end{array}$} & 16 & Cerrado & Nacional \\
\hline & & 18 & Dessalinização das águas & Global \\
\hline & & 22 & Meio natural brasileiro & Nacional \\
\hline & & 28 & $\begin{array}{l}\text { Pesca industrial e destruição na } \\
\text { África }\end{array}$ & Global \\
\hline & & 35 & $\begin{array}{l}\text { Conferência de Quioto/Emissão de } \\
\mathrm{CO}_{2}\end{array}$ & Global \\
\hline
\end{tabular}

Fonte: Provas do ENEM (2012, 2013, 2014, 2015 e 2016).

Conforme ilustra o Quadro 1, quando analisada a crescente do número de questões ao longo dos anos em que as provas de aplicação das provas - aqui analisadas as de Ciências Humanas e suas Tecnologias -, observou-se que houve um aumento do número de questões que tiveram relação com a temática ambiental, sendo três questões no ano de 2012, quatro para 2013, cinco para 2014, seis para 2015 e, novamente, cinco para o ano de 2016. Nessa proporção, é possível observar que a dimensão ambiental aumentou em uma questão por ano na prova de Ciências Humanas, mas que seu espaço ainda é pequeno se considerado o número de disciplinas que compõem essa prova (filosofia, história, geografia e sociologia), permitindo notar que outros temas dentro das ciências humanas e, mesmo nas questões destinadas à geografia, ciência relacionada às ciências ambientais, a dimensão ambiental ainda é pouco abordada. 
Quando analisadas as questões referentes às provas de Ciências da Natureza e suas Tecnologias, das 225 questões, aplicadas nesses cinco anos (2012-2016), apenas 33 sinalizaram a temática socioambiental. Outras questões consideravam tópicos relacionados ao ambiente, mas o fizeram de maneira isolada e superficial e, por isso, não foram consideradas para análise, pois não faziam menção às interações do organismo/fenômeno abordado nos ecossistemas, valorizando o ensino dissociativo, que não aprecia interações socioambientais, contradizendo a própria proposta do exame e o conceito de interdisciplinaridade.

Consoante Leff (2000), a interdisciplinaridade é um processo amplo, que transcende os campos de ensino e pesquisa, indo além das disciplinas científicas comuns, articula os vários campos do saber, e também abriga os espaços de educação não-formais. Desse modo, também pode ser caracterizada pela interação entre as várias disciplinas, indo desde a simples comunicação de ideias à integração de conceitos fundamentais em ciências ambientais.

O Quadro 2 traz a relação de questões, a explanação do conteúdo abordado em cada uma das selecionadas e sua abordagem em uma escala global/nacional, acentuando a escala espacial a que se referem.

Quadro 2 - Análise das questões de Ciências da Natureza e suas Tecnologias (2012-2016) do ENEM.

\begin{tabular}{|c|c|c|c|c|}
\hline Ano & Caderno & Questão & Conteúdo Abordado & Escala \\
\hline \multirow{7}{*}{2012} & \multirow{7}{*}{$\begin{array}{l}\text { Caderno } \\
01\end{array}$} & 46 & Reciclagem & Global \\
\hline & & 47 & Compactação do solo & Global \\
\hline & & 49 & Agrotóxicos & Global \\
\hline & & 51 & Agrotóxicos & Global \\
\hline & & 52 & Saúde ambiental & Global \\
\hline & & 59 & Aquecimento global & Global \\
\hline & & 71 & Matrizes energéticas & Global \\
\hline \multirow{7}{*}{2013} & \multirow{7}{*}{$\begin{array}{l}\text { Caderno } \\
01\end{array}$} & 51 & $\begin{array}{ll}\text { Química } & \text { verde/Matrizes } \\
\text { energéticas } & \end{array}$ & Global \\
\hline & & 54 & Embalagens PET & Global \\
\hline & & 63 & Represamento hídrico & Global \\
\hline & & 67 & Efeito estufa & Global \\
\hline & & 69 & Deposição mineral & Global \\
\hline & & 81 & Tratamento de água & Global \\
\hline & & 84 & Espécies invasoras & $\begin{array}{l}\text { Local } \\
\text { (Angra dos Reis) }\end{array}$ \\
\hline \multirow{10}{*}{2014} & \multirow{10}{*}{$\begin{array}{l}\text { Caderno } \\
04\end{array}$} & 49 & $\begin{array}{l}\text { Poluição térmica/Geração de } \\
\text { energia }\end{array}$ & Global \\
\hline & & 58 & Cerrado & Nacional \\
\hline & & 60 & Ciclo do nitrogênio & Global \\
\hline & & 66 & Resíduos químicos & Nacional \\
\hline & & 67 & Ecossistemas marinhos & Global \\
\hline & & 72 & Camada de ozônio/CFC & Global \\
\hline & & 73 & Resíduos sólidos & Nacional \\
\hline & & 81 & Efluentes químicos & Nacional \\
\hline & & 85 & Biorremediação & Global \\
\hline & & 90 & Reciclagem & Global \\
\hline \multirow{3}{*}{2015} & \multirow{3}{*}{$\begin{array}{l}\text { Caderno } \\
01\end{array}$} & 47 & Poluição das águas & Global \\
\hline & & 61 & Ciclo do nitrogênio & Global \\
\hline & & 90 & Química verde & Global \\
\hline 2016 & & 57 & Mudanças climáticas & Global \\
\hline
\end{tabular}




\begin{tabular}{|l|l|l|l|l|}
\hline \multirow{3}{*}{$\begin{array}{l}\text { Caderno } \\
03\end{array}$} & 62 & $\begin{array}{l}\text { Emissão de } \mathrm{CO}_{2} \text { e qualidade } \\
\text { nutricional }\end{array}$ & Global \\
\cline { 2 - 5 } & 64 & Biomas brasileiros & Nacional \\
\cline { 2 - 5 } & 66 & Sistemas agroflorestais & Nacional \\
\cline { 2 - 5 } & 76 & Teias alimentares & Global \\
\cline { 2 - 5 } & 90 & Biodigestores & Global \\
\hline
\end{tabular}

Fonte: Provas do ENEM (2012, 2013, 2014, 2015 e 2016).

Como aclarado no Quadro 2, de maneira diferente das provas de Ciências Humanas, o número de questões relacionadas à dimensão socioambiental não obedeceu a uma variação crescente entre os anos de aplicação das provas, oscilando na quantidade de questões, que variaram entre diversas temáticas. No entanto, o número de questões que trataram da temática socioambiental nessa prova superou ao da prova de Ciências Humanas. Especificamente, o ano de 2014 exibiu o maior número de questões, destinando 10 delas para a discussão socioambiental nas provas referentes às Ciências da Natureza.

Como a área de Ciências da Natureza e suas Tecnologias se relaciona com as disciplinas de biologia, física e química, o número trazido no ano de 2010 reflete que questões dessa natureza são muito mais discutidas nessa área específica, pois a Biologia é, histórica, natural e cientificamente condicionada à discussão de temas socioambientais, talvez por sua natureza enquanto ciência do ambiente, dos seres vivos e suas inter-relações. Conforme discute Sapatini (2014), ao analisar o perfil das questões das provas de Biologia no ENEM, de 1998 a 2012, uma média de 15 questões por prova são destinadas à Biologia, o que configura um número expressivo, girando em torno de $20 \%$ da prova, tendo em vista as diversas ciências que a compõem.

Ao analisarem a dimensão da temática água, no ENEM, Nascimento e Araújo (2017), comprovaram que as provas de Ciências da Natureza são as que possuem o maior número de questões socioambientais relacionadas à temática pesquisada pelas autoras, sendo bastante expressiva a diferença entre as provas de Ciências da Natureza e as demais do exame. Tal fato sugere, como discutido neste estudo, que os temas socioambientais são abrangidos com maior propriedade nessas provas.

A integração entre as disciplinas do bloco de ciências da natureza com as questões socioambientais, aqui entendidas como tema transversal/motivador, é muito mais observada no tocante às disciplinas de biologia e química, pois apenas uma questão das que foram selecionadas consegue integrar-se com o conteúdo trabalhado na disciplina de física, salientando a comum dificuldade de se inserir tópicos interdisciplinares nas disciplinas da área de exatas, mesmo essa compondo as Ciências da Natureza. Consoante Miranda e colaboradores (2011), a contextualização de saberes discentes vem sendo reformulada de forma ambivalente e antagônica, na tentativa de harmonização de discursos, valorizando práticas alheias à criticidade necessária para a educação para o futuro.

A ideia de universalização do que deve ser ensinado recai em tópicos como: biomas terrestres, aquecimento global, efeito estufa, desmatamento, erosão e demais conteúdos desenvolvidos em disciplinas específicas, de forma desarticulada e pouco participativa, levando o aluno ao conhecimento exaustivo da maior parte dos processos veiculados e, principalmente, discutidos pela mídia, mas que pouco abrange sua realidade. Assim como retratado nos Quadros 1 e 2, formam-se alunos aptos a discutir os efeitos em nível global, mas pouco relacionados aos processos histórico-culturais de âmbito local. Ensina-se a pensar como o sistema deseja ou a ser aprovado em exames que digam ao mundo que eles aprenderam o que era necessário aprender. Mas, aprender para quê(m)? Aprender o quê?

Como afirma Sousa (2003, p. 183): "o ENEM apresenta-se com um potencial maior de condicionar os currículos escolares, ou seja, ensina-se para obter bons resultados no exame". Não obstante, conforme ensina Silva (2016), a política de certificação via ENEM contribuiu 
para a desvalorização do professor, pelo fato de que o interesse dos estudantes interfere na maneira como o docente organiza e elabora sua prática pedagógica com base na proposta do ENEM.

O ENEM desqualifica e desvaloriza o ensino ao determinar que os saberes escolarizados servem apenas para aprovação nos exames vestibulares e, consequentemente, a inserção do estudante no ensino superior. O exame, nessa ótica, vem se constituindo um tipo de educação comprometida com resultados de excelência que refletem a maquiagem de uma obtenção de sucesso na vida. Em vista disso, observa-se que o trabalho docente vem sendo regido por um processo de autointensificação, pois os professores sentem-se responsáveis pelo êxito dos estudantes no ENEM, já que esta avaliação vem se configurando como indicadora de parâmetros de qualidade da educação brasileira (SILVA, 2016).

Em consonância com Freitas (2014, p. 1097-1098),

o fato de as escolas agirem sob motivação externa, sem que haja um movimento na própria cultura da escola que se aproprie de seus problemas, reflita, recrie e participe dos processos de melhoria, bloqueia e agrava as relações de ensino. [Desse modo], $[\ldots]$ não resolvem os problemas das brechas de aprendizagem [...] e, portanto, têm consequências não controladas dentro das escolas, afetando a vida de professores, estudantes, diretores e pais de alunos.

Conforme as reflexões trazidas até aqui, pode-se questionar como fica o movimento de (re)construção das práticas pedagógicas quando a escola e seu corpo docente têm sua autonomia limitada às habilidades e competências do ENEM ou ao conceito de escola de resultados? Apresentado desde o início como inovador e contextualizado, o modelo de prova do ENEM tende a impactar os materiais didáticos - ainda que boa parte destes materiais seja mera compilação de provas já realizadas - mas, principalmente, a sinalizar alguns caminhos e critérios para o ensino (BORNATTO, 2013).

Para Gonçalves Júnior (2014), a compreensão e entendimento desse tipo de avaliação tornam-se fundamentais, principalmente para os professores, a partir do momento que, ao servir de base para as ações das políticas públicas em educação, as provas passam a determinar, direta e indiretamente, o currículo a ser ensinado, a carga horária das disciplinas e, finalmente, o perfil dos alunos que ingressam nas universidades.

Em EA usa-se muito o lema "pensar global e agir local" como justificativa dedutiva de se valorizarem ações locais com a projeção de benefícios para a sociedade mundial. Essa necessidade de justificativa nos projetos pode soar até mesmo como uma descrença por quem o idealiza, quando observado que determinada ação só tem valor ao surtir efeito em escalas globais ou quando o aluno crê que está auxiliando povos tradicionais ou ecossistemas inteiros fora do seu alcance em detrimento de ações em seu entorno ou para sua comunidade. Logo, os feitos em EA são praticados e vistos apenas através de imagens de livros ou durante aulas de disciplinas específicas da sua formação, baseadas estritamente no currículo escolar, não compondo a realidade objetiva da educação: a construção do cidadão local, sendo formado o cidadão do mundo, e não do seu lugar.

As atitudes mencionadas no parágrafo anterior podem ser realizadas sem a percepção do docente que toma frente do projeto ou ação, como aqui já discutido, pela simples questão da formação ambiental que recebeu: desarticulada e pouco participativa. Contudo, amplia-se profundamente na necessidade de elaboração de tópicos que são trabalhados em todo o mundo, configurando a realidade local como algo secundário ou irrelevante. Assim, o ensino é focado no que está presente nas avaliações (tanto conteúdo como disciplinas), ficando o restante esquecido ou em segundo plano. 


\section{Considerações Finais}

A formação das pessoas no que toca à sua postura e relação com o ambiente perpassa por várias barreiras, que vão desde seus ensinamentos enquanto homens e mulheres, seres sociais, àquelas que são construídas através das relações sociais em ambientes específicos, como a escola. De forma não diferente, as concepções sobre o ambiente, seja ele visto como um meio natural isolado ou dotado de relações culturais, econômicas e sociais, como recurso ou essência, encontra no ambiente escolar um espaço para discutir, refletir e moldar paradigmas para que tais manifestações sejam propostas de maneira crítica, reflexiva e emancipatória.

Nesse sentido, retoma-se à questão de pesquisa levantada no início da argumentação apresentada por este trabalho: a escola contemporânea, que volta suas práticas para o ENEM, com a utilização de sistemas de ensino direcionados a esse exame, discute aspectos socioambientais de maneira eficaz, uma vez que a transversalidade do meio ambiente é algo complexo e que necessita de formação integral e holística?

Conclui-se que, apesar de o ENEM ter trazido novas propostas à educação básica, levando à discussão sobre a capacidade do aluno (suas competências e habilidades) enquanto cidadão global e modificador do ambiente, ao pensar e refletir sobre problemas socioambientais, faz-se insuficiente e dissociado da realidade local. Ao passo que exclui as características das distintas regiões do país, seus processos de formação e diferentes sistemas ambientais, o exame privilegia a apropriação de conceitos universais em detrimento dos valores históricos, culturais e sociais dos educandos, como comprovado pelo número de questões que tratam de aspectos em escala geográfica local, apesar de o ENEM ser um exame nacional, que deveria tratar como prioridade os aspectos de formação do seu povo. Tais fatos fazem que a escola se restrinja à sua matriz, deixando de lado a originalidade e as necessidades e demandas das comunidades às quais ela se integra, bem como a autonomia docente.

A escola, que antes possuía dificuldades em desenvolver ações contínuas de EA junto aos docentes no andamento de suas disciplinas, agora vive um empasse entre o que é necessário ser aprendido para uma efetiva tomada de decisão frente aos problemas locais e aquilo que deve ser ensinado para que os alunos não sejam prejudicados ao realizar o ENEM. Contudo, as boas ações praticadas no ambiente escolar - e para além dos seus muros - podem e devem ser construídas diariamente através de projetos integradores, que abranjam o cotidiano das mais remotas localidades do seu convívio para, então, a escala geográfica ir tomando maiores proporções.

Mediante o dizer característico "pensar global e agir local", o mais apropriado para ações interdisciplinares e que promovem a formação holística do educando enquanto cidadão crítico e reflexivo, tal qual preconiza a Constituição Federal e a PNEA, é que seja pensada uma EA num contexto de integração de escalas geográficas, valorizando a formação do cidadão do lugar, levando em consideração os valores daqueles que vivem diariamente a escola e, corroborando com isso, visualizar criticamente os instrumentos didáticos, como o livro, que ditam as posturas docente e discente e a forma como os conceitos socioambientais são discutidos.

\section{Referências}

ALTHUSSER, L. Ideologia e aparelhos ideológicos do Estado. 3. ed. Lisboa: Presença/Martins Fontes, 1980.

BAUER, A.; ALAVARSE, O. M.; OLIVEIRA, R. P. Avaliações em larga escala: uma sistematização do debate. Educação e Pesquisa, São Paulo, v. 41, n. especial, p. 1367-1382, dez., 2015. 
BELTRÃO, J. A. A Educação Física na escola do vestibular: as possíveis implicações do ENEM. Movimento, Porto Alegre, v. 20, n. 2, p. 819-840, abr.-jun., 2014.

BORNATTO, S. P. A redação do ENEM e a formação docente. In: CONGRESSO NACIONAL DE EDUCAÇÃO, 11., 2013, Curitiba. Anais... Curitiba: Pontifícia Universidade Católica do Paraná, 2013. p. 5683-5695.

BRASIL. Constituição da República Federativa do Brasil. Brasília, DF: Senado Federal: Centro Gráfico, 1988.

BRASIL. Instituto Nacional de Estudos e Pesquisas Educacionais Anísio Teixeira. Portaria $n^{o} 438$, de 28 de maio de 1998. Institui o Exame Nacional do Ensino Médio - ENEM. Brasília, DF, 1998.

BRASIL. Lei n ${ }^{\circ}$ 6.795, de 27 de abril de 1999. Dispõe sobre a Educação Ambiental, institui a Política Nacional de Educação Ambiental e dá outras providências. Diário Oficial da República Federativa do Brasil, Brasília, DF, 28 abr. 1999.

CALLAI, H. C. A geografia e a escola: muda a geografia? Muda o ensino? Terra Livre, São Paulo, n. 16, p. 133-152, 2001.

CALLAI, H. C. O estudo do lugar como possibilidade de construção da identidade e pertencimento. In: CONGRESSO LUSO-AFRO-BRASILEIRO DE CIÊNCIAS SOCIAIS, 8., 2004, Coimbra. Anais... Coimbra, 2004. p. 1-10. Disponível em: 〈https://bit.ly/2Sd9wAj〉. Acesso em: 8 jul. 2018.

FREITAS, L. C. Os reformadores empresariais da educação e a disputa pelo controle do processo pedagógico na escola. Educação e Sociedade, Campinas, v. 35, n. 129, p. 1085-1114, out.-dez., 2014.

GONÇALVES JÚNIOR, W. P.; BARROSO, M. F. As questões de física e o desempenho dos estudantes no ENEM. Revista Brasileira de Ensino de Física, São Paulo, v. 36, n. 1, p. 1-16, 2014.

GUSMÃO, A. D. F. Os prismas da geografia no exame nacional do ensino médio (ENEM): abordagem conceitual e temática da ciência geográfica na avaliação de 2015. In: ENCONTRO NACIONAL DE GEÓGRAFOS, 13., 2016, São Luís. Anais... São Luís: Universidade Federal do Maranhão, 2016.

LEFF, E. Complexidade, interdisciplinaridade e saber ambiental. In: PHILLIPPI JR., A.; et al. (Org.). Interdisciplinaridade em ciências ambientais. São Paulo: Signus, 2000. p. 19-51.

LEFF, E. Complexidade, Racionalidade Ambiental e Diálogo de Saberes. Educação e Realidade, Porto Alegre, v. 34, n. 3, p. 17-24, set.-dez., 2009a.

LEFF, E. Saber ambiental: sustentabilidade, racionalidade, complexidade, poder. 7. ed. Petrópolis: Vozes, 2009b.

MACEDO, J. D. F.; MEDEIROS, R. M. Formações ideológicas materializadas nas condições de produção do novo ENEM. In: SIMPÓSIO BRASILEIRO DE POLÍTICA E 
ADMINISTRAÇÃO DA EDUCAÇÃO, 25., 2011, São Paulo. Anais... São Paulo: Pontifícia Universidade Católica de São Paulo, 2011. p. 1-10.

MIRANDA, E. M.; et al. ENEM 2009: articulações entre CTS, interdisciplinaridade e contextualização evidenciadas nas questões de Ciências da Natureza. In: ENCONTRO NACIONAL DE PESQUISA EM EDUCAÇÃO EM CIÊNCIAS, 8., 2011, Campinas. Anais... Campinas: Universidade Estadual de Campinas, 2011. p. 1-12.

NASCIMENTO, J. E. A.; ARAÚJO, M. L. F. A dimensão ambiental da temática água no Exame Nacional do Ensino Médio. Revista Eletrônica do Mestrado em Educação Ambiental, Rio Grande, v. 34, n. 1, p. 148-167, jan.-abr., 2017.

REIS, L. C. L.; SEMÊDO, L. T. A. S.; GOMES, R. C. Conscientização Ambiental: da Educação formal a não formal. Revista Fluminense de Extensão Universitária, Vassouras, v. 2, n. 1, p. 47 60, jan.-jun. 2012.

SÁ, P. R.; FERREIRA, L. G. Livro didático de língua portuguesa: contribuições e implicações em sala de aula nas séries iniciais. Espaço Pedagógico, Passo Fundo, v. 22, n. 1, p. 136-154, jan.-jun., 2015.

SANTOS, L. R. O.; COSTA, J. J.; MELO E SOUZA, R. High school national examination and its implications for environmental science teaching. Revista Eletrônica em Gestão, Educação e Tecnologia Ambiental, Santa Maria, v. 21, n. 3, p. 232-239, set.-dez., 2017.

SANTOS, L. R. O.; COSTA, J. J.; MELO E SOUZA, R. Exame Nacional do Ensino Médio: desafios para o ensino das ciências ambientais em escala local. Revista Eletrônica do Mestrado em Educação Ambiental, Rio Grande, v. 35, n. 1, p. 4-20, $2018 \mathrm{a}$.

SANTOS, L. R. O.; COSTA, J. J.; MELO E SOUZA, R. Práticas pedagógicas de educação ambiental e o Exame Nacional do Ensino Médio: implicações curriculares. In: SILVA, M. S. F.; CARVALHO, M. E. S.; SANTOS, N. D.; COSTA, J. J. Reflexões teórico-metodológicas \& práticas pedagógicas nas Ciências Ambientais. São Cristóvão: Editora UFS, 2018b. p. 308327.

SAPATINI, J. R. Categorização e análise das questões de biologia do ENEM (1998-2012). 2014. 44 f. Monografia (Especialização em Ensino de Ciências) - Universidade Tecnológica Federal do Paraná, Medianeira, 2014.

SILVA, S. G. ENEM: implicações no currículo e no trabalho docente em educação de jovens e adultos. In: REUNIÃO CIENTÍFICA REGIONAL DA ANPED - ANPED SUL, 11., 2016, Curitiba. Anais... Curitiba: Universidade Federal do Paraná, 2016. p. 1-15.

SOUSA, S. Possíveis impactos das políticas de avaliação no currículo escolar. Cadernos de Pesquisa, São Paulo, n. 119, p. 175-190, jul., 2003. 